\title{
Tratamento alternativo para germinação de sementes de mulungu (Erythrina velutina)
}

\author{
Rivaildo da Costa Nascimento ${ }^{1}$, Leandro Justino da Silva ${ }^{2}$, Vitória Saskia Ferreira Barroso ${ }^{3}$, Élida Barbosa Corrêa ${ }^{* 4}$ \\ Universidade Estadual da Paraíba, ${ }^{1}$ rivaagro10@gmail.com; ${ }^{2}$ leojustinosilva@ gmail.com; ${ }^{3}$ vitoriasaskia17@ gmail.com; \\ 4*elida.uepb@gmail.com.
}

\begin{abstract}
RESUMO: O mulungu é uma árvore endêmica da Caatinga e utilizada popularmente no tratamento da ansiedade e de outras doenças. $\mathrm{O}$ objetivo do trabalho foi avaliar emergência e desenvolvimento de mudas de mulungu por meio do tratamento de sementes com produtos alternativos. Após a coleta das sementes foi realizada a escarificação mecânica e tratamento com: biofertilizante, extrato de alho, pó-de-rocha, biofertilizante + extrato de alho, biofertilizante + pó-derocha, extrato de alho + pó-de-rocha e biofertilizante + extrato de alho + pó-de-rocha por meio da imersão por 10 min. Após o tratamento das sementes, as mesmas foram semeadas em sacos para produção de mudas contendo solo acrescido de esterco bovino. A emergência foi avaliada após cinco dias e o desenvolvimento das mudas após 15 dias. O tratamento de sementes de mulungu com pó-de-rocha + biofertilizante promoveu a emergência das sementes em $95 \%$, no entanto não diferiu da testemunha (45\%) pelo teste de Kruskall-Wallis. Os tratamentos aplicados nas sementes não influenciaram o desenvolvimento do número de folhas, altura e diâmetro do caule das mudas de mulungu. Conclui-se que o tratamento de sementes de mulungu com pó-de-rocha + biofertilizante têm potencialidade para promover a emergência das sementes.
\end{abstract}

PALAVRAS-CHAVE: Pó-de-rocha; Biofertilizante; Extrato de alho; Peletização; Escarificação.

\section{INTRODUÇÃO}

Árvore endêmica da Caatinga, o mulungu pertence à divisão Angiospermae, ordem Fabales, família Fabaceae, subfamília Faboideae, gênero Erythrina e espécie Erythrina velutina. A origem do nome vulgar do mulungu vem do tupi, mussungú ou muzungú e também do africano mulungu, como significado de "pandeiro" (CARVALHO, 2008). O mulungu é uma planta com características medicinais, sendo utilizado na medicina tradicional para o tratamento de doenças do sistema nervoso central, verminose e tosse (AGRA et al., 2008). Em revisão realizada por Sousa et al. (2008) os autores descrevem o efeito ansiolítico dos extratos feitos com inflorescências da planta.

Medicamentos fitoterápicos têm vantagens preventivas, terapêuticas e em efeitos colaterais sobre os medicamentos sintéticos (MICHILES, 2004). Além das vantagens terapêuticas, medicamentos fitoterápicos têm menor custo do que medicamentos alopáticos; o que tem suscitado instituições públicas a promoverem a sua utilização entre as comunidades. Uma forma de promoção do uso de medicamentos fitoterápicos é a instalação de Farmácias Vivas com plantas medicinais indicadas para o tratamento das principais doenças que acometem a comunidade.

Durante o processo de germinação as sementes podem ser infectadas por diversos patógenos que habitam o solo, sendo que, quanto mais rápida a germinação, maior o período de escape às condições favoráveis a ocorrência de doenças. Em sistemas de cultivos de plantas medicinais a qualidade das sementes e mudas é extremamente importante para a produção das culturas; pois a utilização de sementes e mudas sadias garante a sanidade do cultivo e promove a resistência natural das plantas; além de influenciar o número de ciclos produtivos durante o ano (CARMELLO, 1995).

A peletização de sementes com pó-de-rocha e biofertilizante é recomendada pelo Ministério de Agricultura, Pecuária e Abastecimento (MAPA), por meio de suas Fichas Agroecológicas para proteger as sementes contra fatores externos, promovendo a germinação (aceleração da germinação em torno de cinco dias), o vigor e a sanidade; pois as raízes recém emitidas entram em contato com os nutrientes presentes na mistura pó de rocha + biofertilizante promovendo o seu desenvolvimento e aumentando a resistência das plântulas a fatores adversos (Leite, 2017). O pó de rocha MB-4, de acordo com a empresa produtora, é proveniente de rochas selecionadas e libera nutrientes necessários para atender as exigências das plantas e microbiota, fortalecendo as plantas contra o ataque de pragas e doenças (MB-4, 2019). Dentre os produtos alternativos utilizados para o tratamento de doenças podemos citar os extratos feitos com bulbilhos de alho (Allium sativum), tendo a planta comprovada eficiência antimicrobiana (Ministério da Saúde, 2015).

As mudas de mulungu produzidas no presente trabalho foram doadas em ação de Educação Ambiental feita no município de Tenório/PB, pois o presente trabalho compreende uma das linhas de ação do projeto "Tecnologias sociais e educação ambiental para o controle vetorial de arboviroses: promovendo a saúde e a qualidade de vida no semiárido paraibano" que visa a instalação de farmácias vivas nos municípios que compreendem o projeto.

De acordo com a importância do mulungu como planta medicinal, sendo utilizada na arborização urbana e na recomposição florestal, o objetivo do trabalho foi avaliar emergência e desenvolvimento de mudas de mulungu por meio do tratamento de sementes com pó-de-rocha, biofertilizante, extrato de alho, aplicados isoladamente ou em conjunto. 
NASCIMENTO, R. C. et al. Tratamento alternativo de sementes de mulungu (Erythrina velutina). In: II Congresso Paraibano de Agroecologia \& IV Exposição Tecnológica, 2019. Anais.... Caderno Verde de Agroecologia e Desenvolvimento Sustentável, Pombal, v. 9, n.7, e-7066, 2019.

\section{MATERIAL E MÉTODOS}

A pesquisa foi conduzida no Centro de Ciências Agrárias e Ambientais (CCAA) da Universidade Estadual da Paraíba (UEPB) no Laboratório de Fitopatologia e campo experimental, no período compreendido de março a agosto de 2018, localizado no município de Lagoa Seca/PB; tendo as coordenadas de latitude 709 S, longitude $3552 \mathrm{~W}$ e altitude de 634 m (SOARES et al., 2017)

\section{Produtos alternativos utilizados para o tratamento de sementes}

O biofertilizante foi formulado com os seguintes materiais: $0,673 \mathrm{~kg}$ de sangue de aves; $50,0 \mathrm{~kg}$ de vinhaça; 2,5 $\mathrm{kg}$ de coração de bananeira triturado; $0,1 \mathrm{~kg}$ de cinza de madeira, 7,2 $\mathrm{kg}$ de manipueira e 139,5 L de água, misturados forma a fica homogêneo em tambor de 200 L, sendo aerado mexendo-o a cada sete dias por um tempo de fermentação de 90 dias.

Extrato aquoso de alho foi preparado utilizando-se bulbilhos. Os bulbilhos foram acondicionados em estufa de circulação de ar forçada por três dias. Após a secagem, $100 \mathrm{~g}$ dos bulbilhos foram acondicionados em $900 \mathrm{~mL}$ de água destilada autoclavada, sendo a mistura acondicionada em geladeira $\left(4^{\circ} \mathrm{C}\right)$ por 24 horas. Depois de ocorrida a maceração, o extrato aquoso de alho foi filtrado e utilizado.

O pó-de-rocha utilizado no experimento foi o MB-4 (MB-4, MIBASA) .

Sementes de mulungu foram coletadas no município de Lagoa Seca/PB (coordenadas 709'19.6"S $35^{\circ} 52^{\prime} 17.7^{\prime \prime W}$ ) e processadas no Campus II da UEPB. A quebra de dormência foi realizada por meio da escarificação das sementes com lixa D’água número 200 na porção basal da semente evitando danificar o hilo. As sementes foram selecionadas e escarificadas com movimentos retilíneos na lixa durante 3 a 5 movimentos retilíneos com a base da semente tocando na lixa.

Para o tratamento das sementes foi realizada a imersão por 10 minutos de 20 sementes para cada um dos oito tratamento em um volume final de $3 \mathrm{~mL}$, sendo os seguintes: água (testemunha), pó-de-rocha (4,5 g / $3 \mathrm{~mL}$ de água), biofertilizante $(20 \%)$ + extrato de alho $(100 \%)$, biofertilizante $(20 \%)+$ pó-de-rocha $(4,5 \mathrm{~g} / 3 \mathrm{~mL}$ de suspensão de biofertilizante), extrato de alho $(100 \%)+$ pó-de-rocha $(4,5 \mathrm{~g} / 3 \mathrm{~mL}$ de extrato de alho) e biofertilizante $(20 \%)+$ extrato de alho (concentração $100 \%)$ + pó-de-rocha $(4,5 \mathrm{~g} / 3 \mathrm{~mL}$ de suspensão) por meio da imersão por $10 \mathrm{~min}$, em becker com capacidade para $100 \mathrm{ml}$.

As sementes de mulungu foram adicionadas em sacos plásticos (3L) com substrato em capacidade de campo, sendo duas sementes por saco totalizando 160 sementes em 80 sacos. O desbaste das sementes foi realizado após 15 dias, deixando-se uma planta por saco. Utilizou-se substrato na proporção de três partes de solo e duas partes de esterco bovino para o desenvolvimento das mudas. A emergência das sementes foi avaliada após cinco dias da semeadura e a avaliação do desenvolvimento das mudas por meio da altura, diâmetro do caule e número de folhas foi avaliado após 15 dias da semeadura.

O delineamento experimental foi inteiramente casualizado, sendo testados oito tratamentos com 10 repetições para o teste de emergência, nas quais quatro repetições por tratamento foram destinadas para as avaliações de altura, diâmetro do caule e número de folhas. As análises estatísticas foram realizadas por meio do programa estatístico Action ${ }^{\circledR}$, sendo realizado o teste de normalidade e homogeneidade de variâncias. Após verificada a distribuição dos dados, realizou-se análise estatística não paramétrica pelo teste de Kruskal-Wallis e de médias para os dados paramétricos com teste de Tukey.

\section{RESULTADOS E DISCUSSÃO}

O tratamento de sementes de mulungu com pó-de-rocha + biofertilizante promoveu a emergência das sementes, sendo de $95 \%$ após cinco dias da semeadura. No entanto, não diferenciou da testemunha pelo teste não-paramétrico de Kruskall-Wallis (Tabela 01). Os tratamentos com biofertilizante e extrato de alho tiveram efeito negativo na germinação das sementes; e como tratamento com pó-de-rocha + biofertilizante, não diferenciaram da testemunha (Tabela 01). A altura, número de folhas e o diâmetro do caule não foram influenciados pelos tratamentos (Tabela 1). 
NASCIMENTO, R. C. et al. Tratamento alternativo de sementes de mulungu (Erythrina velutina). In: II Congresso Paraibano de Agroecologia \& IV Exposição Tecnológica, 2019. Anais.... Caderno Verde de Agroecologia e Desenvolvimento Sustentável, Pombal, v. 9, n.7, e-7066, 2019.

Tabela 01. Porcentagem de germinação de sementes (após cinco dias da semeadura), número de folhas, altura e diâmetro do caule de mulungu após 15 dias dos tratamentos com pó-de-rocha, extrato de alho, pó-de-rocha + extrato de alho, pó-de-rocha + biofertilizante, pó-de-rocha + biofertilizante + extrato de alho.

\begin{tabular}{lcccc}
\hline \multicolumn{1}{c}{ Tratamentos } & $\begin{array}{c}\text { Emergência de } \\
\text { sementes }(\boldsymbol{\%})\end{array}$ & Altura (cm) & $\begin{array}{c}\text { Número de } \\
\text { folhas }\end{array}$ & $\begin{array}{c}\text { Diâmetro do } \\
\text { caule (cm) }\end{array}$ \\
\hline \hline Testemunha & $45 \mathrm{ab}^{*}$ & $21,32 \mathrm{a}^{* *}$ & $2 \mathrm{a} * *$ & $3,86 \mathrm{a}^{* *}$ \\
\hline \hline Pó de rocha & $70 \mathrm{ab}$ & $26,5 \mathrm{a}$ & $3 \mathrm{a}$ & $4,71 \mathrm{a}$ \\
\hline Biofertilizante & $30 \mathrm{~b}$ & $27,3 \mathrm{a}$ & $3,75 \mathrm{a}$ & $4,55 \mathrm{a}$ \\
\hline \hline Extrato de alho & $40 \mathrm{~b}$ & $24,7 \mathrm{a}$ & $2,75 \mathrm{a}$ & $4,36 \mathrm{a}$ \\
\hline \hline Extrato de alho + biofertilizante & $45 \mathrm{ab}$ & $23,87 \mathrm{a}$ & $3 \mathrm{a}$ & $4,62 \mathrm{a}$ \\
\hline \hline Pó de rocha + extrato de alho & $70 \mathrm{ab}$ & $25,5 \mathrm{a}$ & $3 \mathrm{a}$ & $4,58 \mathrm{a}$ \\
\hline Pó de rocha + biofertilizante & $95 \mathrm{a}$ & $28 \mathrm{a}$ & $3,25 \mathrm{a}$ & $4,99 \mathrm{a}$ \\
\hline \hline $\begin{array}{l}\text { Pó de rocha + biofertilizante }+ \text { extrato } \\
\text { de alho }\end{array}$ & $65 \mathrm{ab}$ & $26,8 \mathrm{a}$ & $3,25 \mathrm{a}$ & $4,80 \mathrm{a}$
\end{tabular}

*Dados seguidos pela mesma letra não diferenciaram pelo teste de Kruskall-Wallis a 5\%. ** Dados não diferenciaram pelo teste de Tukey a 5\%. ***Dados seguidos pela mesma letra não diferenciaram pelo teste de Kruskall-Wallis a 5\%.

Apesar de não diferenciar estatisticamente da testemunha, as sementes que receberam o tratamento com pó de rocha + biofertilizante tiveram a maior porcentagem de emergência, quando comparadas aos demais tratamentos testados (Tabela 01). De acordo com as Fichas Agroecológicas do MAPA a peletização de sementes com a mistura de pó de rocha + biofertilizante acelera a germinação das sementes (Leite, 2017).

Biofertilizante a $20 \%$ teve efeito negativo na emergência das sementes, quando comparados ao tratamento onde o biofertilizante foi associado ao pó-de-rocha (Tabela 01). No entanto, a aplicação de biofertilizante a $30 \%$ influenciou positivamente o desenvolvimento de plântulas de cupuaçu (SOARES et al., 2014). Assim como para o tratamento com biofertilizante, o tratamento das sementes com extrato de alho teve efeito negativo na emergência das sementes (Tabela 01). A escarificação das sementes de mulungu pode ter potencializado o efeito de biofertilizante e extrato de alho nas sementes, causando fitotoxidez nas plântulas.

\section{CONCLUSÃO}

Conclui-se apartir da pesquisa que o tratamento de sementes de mulungu com pó-de-rocha + biofertilizante têm potencialidade para promover a emergência das sementes.

\section{REFERÊNCIAS}

AGRA MF, SILVA KN, BASÍLIO IJLD, FRANÇA PF, BARBOSA-FILHO JM 2008. Survey of medicinal plants used in the region Northeast of Brazil. Brazilian Journal of Pharmacognosy, 18: 472- 508.

CARMELLO, Q.A.C. Nutrição e adubação de mudas hortícolas. In: MINAMI, K. Produção de mudas de alta qualidade em horticultura. São Paulo: T.A. Queiroz, 1995. p. 33-37.

CARVALHO, P.E.R. Mulungu (Erythrina velutina). Circular Técnica 160. 2008. 8p.

LEITE, C. D.; MEIRA, A. L., MOREIRA, V.R.R.Peletização de sementes com uso de biofertilizante e pó de rocha: Fertilidade do solo e nutrição das plantas. Fichas Agroecologicas. Disponível em: http://www.agricultura.gov.br/assuntos/sustentabilidade/organicos/fichas-agroecologicas/arquivos-fertilidade-dosolo/30-peletizacao-de-sementes-com-uso-de-biofertilizante-e-po-de-rocha.pdf. Acesso em 20 ago. de 2019.

MB-4.MIBASA: Mineração Barreto. Disponível em: http://mibasa.agenciafish.webfactional.com/produto/mb4/17/ Acesso em 09 de set. de 2019.

MICHILES, E. Diagnóstico situacional dos serviços de terapia no Estado do Rio de Janeiro. Revista Brasileira de Farmacognosia, v. 14, Suplemento 01, p.16-19,2004.

MONOGRAFIA DA ESPÉCIE Allium sativum (ALHO). Ministério da Saúde. Brasília, 2015, 66p.

SOARES, E. R.; BASEGGIO, E. A.; SENA, S. P.; PEREIRA, M. D.Emergência e desenvolvimento inicial de plântulas de cupuaçu em substrato enriquecido com biofertilizante. Revista Brasileira de Agroecologia. v. 9, n.1, p. 176-184, 2014. 
NASCIMENTO, R. C. et al. Tratamento alternativo de sementes de mulungu (Erythrina velutina). In: II Congresso Paraibano de Agroecologia \& IV Exposição Tecnológica, 2019. Anais.... Caderno Verde de Agroecologia e Desenvolvimento Sustentável, Pombal, v. 9, n.7, e-7066, 2019.

SOARES,C. S.,SILVA, J. A.da,SILVA,G. N.da. Produção de coentro em diferentes espaçamentos dos canais hidroponicos, Pesquisa agropecuária Pernambucana, v. 22, pp.1-5,2017

https://pap.emnuvens.com.br/pap/article/view/pap.2017.001. Acesso em 21 de set. de 2019.

SOUSA, F.C.F.; MELO, C.T.V.; CITÓ, M.C.O.; FÉLIX, F.H.C.; VASCONCELOS, S.M.N.; FONTELES, M.M.F.; BARBOSA FILHO, J.M.; VIANA, G.S.B. Plantas medicinais e seus constituintes bioativos: Uma revisão da bioatividade e potenciais benefícios nos distúrbios da ansiedade em modelos animais. Brazilian Journal of Pharmacognosy, v.18, n.4, p. 642-654, 2008.

\section{AGRADECIMENTOS}

Apoio financeiro: Fundação de Apoio à Pesquisa do Estado da Paraíba - FAPESQ. 